\title{
Inserção social como função política da universidade: resistências e perspectivas
}

\section{Social insertion as a political function of the university: resistance and perspectives}

\author{
Maria Liduína de Oliveira e Silva ${ }^{a}$ \\ (D) https://orcid.org/0000-0002-7904-4836 \\ Sônia Regina Nozabiellia \\ (1) https://orcid.org/0000-0002-1381-3057 \\ Terezinha de Fátima Rodrigues ${ }^{a}$ \\ (D https://orcid.org/0000-0002-8639-7509
}

Resumo: Este artigo apresenta apontamentos referentes à inserção social a partir da experiência do Programa de Pós-Graduação em Serviço Social e Políticas Sociais (PPGSSPS) na Baixada Santista. Objetiva contribuir com o debate da inserção social e sistematizar percursos e ações que evidenciem o empenho do programa na materialização dessa função em um contexto de contrarreformas do Estado, de ataques à educação e de profundas desigualdades sociais.

Palavras-chave: Inserção social. Pós-graduação. Baixada Santista. Serviço Social. Políticas sociais.
Abstract: This article presents notes regarding social insertion from experience of Graduate Program in Social Work and Social Policies (PPGSSPS), in Baixada Santista. It aims to contribute with the debate of social insertion and to systematize paths and actions that highlight the Program's commitment in materialization of this function in a context of counter-reforms of the State, attacks on education and profound social inequalities.

Keywords: Social insertion. Post-graduate. Baixada Santista. Social Work. Social policies. 


\section{Introdução}

PPGSSPS da Universidade Federal de São Paulo (Unifesp), campus Baixada Santista, tem um vínculo de origem com a graduação, que desde que foi implantada apontou a perspectiva de abertura do mestrado acadêmico, de modo a projetar a criação dessa área de conhecimento na universidade.

Desde então, o curso de graduação e o PPGSSPS vêm construindo relações de proximidade e colaboração, estabelecendo uma cultura político-acadêmica importante e necessária no ambiente universitário (Amaral, 2012).

O PPGSSPS teve início em 2016, em uma conjuntura de retrocessos da política educacional brasileira em que se "consolidam um processo de sucateamento do ensino em todos níveis reverberando na pós-graduação, o que põe em risco o seu padrão de qualidade acadêmica" (Guerra, 2011, p. 137).

As transformações e exigências de viés neoliberal contidas nos últimos planos nacionais de pós-graduação, as discussões sobre a gestão da pesquisa e a produção do conhecimento na sociedade globalizada, as estratégias em curso de articulação entre o Estado, a universidade e as empresas (tríplice hélice), os cortes e contingenciamentos de recursos impostos às universidades e ao setor público atingem suas atividades por inteiro (Mendes, Werlang e Santos, 2017).

Nesse contexto de contrarreformas do Estado e de ataques à educação pública, o programa teve sua implantação em um período de dificuldades e desafios marcados pela ofensiva do pensamento conservador, consequente desqualificação do conhecimento crítico e predomínio de interesses privatistas que vêm destruindo a educação pública.

Ao invocar o tema da inserção social do PPGSSPS, pretende-se identificar práticas que evidenciem o seu posicionamento, resistência e compromisso social e político com as necessidades sociais, bem como a vitalidade da área em desenvolver atividades sintonizadas com os fundamentos da formação e com os valores do projeto profissional. 


\section{Inserção social do PPGSSPS no contexto da Baixada Santista}

O marco do debate nacional sobre a inserção social encontra-se em um texto de Renato Janine Ribeiro, então diretor de avaliação da Capes, divulgado em 2007, que apresenta como novidade este quesito na ficha de avaliação da pós-graduação. $O$ texto destaca que essa inovação implica o reconhecimento da responsabilidade social da pós-graduação, que "deve, assim, não apenas melhorar a ciência, mas também melhorar o país" (Ribeiro, 2007, p. 2). Indica a autonomia das áreas do conhecimento na definição da concepção de inserção social e aponta quatro exemplos: impacto tecnológico/econômico, impacto educacional, impacto propriamente social e o impacto cultural.

As reflexões de Boufleuer (2009) sobre a inserção social como quesito de avaliação da pós-graduação trazem importantes elementos. Se considerarmos a inserção social como dimensão inerente e constitutiva da pós-graduação, seria redundante abordá-la. $O$ autor adverte que não se trata de "um passo adiante" nas atividades da pós-graduação, não exige um "fazer a mais", pois a inserção social representa "todo empenho, pontual ou sistemático, voltado para a supressão desse hiato verificável entre a pesquisa e a aprendizagem no âmbito da pós-graduação e a sua aplicação, presença ou seu impacto no âmbito da sociedade" (Boufleuer, 2009, p. 378).

Em face desses elementos, a concepção de inserção social expressa o modo como a pós-graduação articula o seu "fazer" com as necessidades sociais, se compromete e se comunica com a sociedade "em sentido de retroalimentação ou de recíproca fecundação entre o conhecimento acadêmico e as práticas sociais e culturais" (Idem, p. 381).

Tem-se, portanto, apontamentos para a tematização da inserção social, de sua contribuição na melhoria não só da "ciência", mas do "país". Subjaz a esse entendimento a inexistência ou fragilidade de vínculos orgânicos entre a pós-graduação e a sociedade. Nessa perspectiva, cabe perguntar: qual "impacto social”, quais interesses da sociedade? 
Responder esses apontamentos exige posicionamentos políticos vinculados a projetos societários. E aqui se coloca um campo aberto de tensões na política educacional brasileira que se espraia entre as áreas do conhecimento em relação à direção ético-política do compromisso com a sociedade que passa por diferentes concepções: instrumentalização do conhecimento; empresariamento das pesquisas; formação para o mercado de trabalho; defesa de direitos sociais e humanos; fortalecimento das lutas sociais e valorização de conhecimentos que respondam aos desafios da realidade brasileira.

Deve-se enfatizar que essa construção da função política da inserção social é disputada cotidianamente pela direção nacional da política educacional que vem firmando seu viés neoliberal, privatista e tecnicista da formação profissional. Assim, escassos recursos destinados à pesquisa no setor público "passam a ser compartilhados com o setor privado, objetivando potencializar a inovação, o empreendedorismo e o aumento da competitividade e da produtividade das economias" (Mendes, Werlang e Santos, 2017, p. 166).

Nesse contexto, "em tempos de fissuras do neoliberalismo no mundo, o ambiente acadêmico torna-se espaço estratégico no sentido de refletir, analisar e propor alternativas" que disputem espaços e a direção das políticas educacionais (Amaral, 2012, p. 231).

Estudos de Guerra (2011), Amaral (2012), Abepss (2015), Mendes, Santos e Werlang (2017), problematizam o cenário da política nacional de pós-graduação no Brasil, situam as implicações para a área de Serviço Social e apresentam subsídios críticos para a apreensão de desafios e possibilidades. Conforme assevera Guerra (2011) a pós-graduação stricto sensu em Serviço Social, amadureceu, se fez respeitar, acumulou potencialidades e construiu um espaço que detém vitalidade e possibilidades em razão de seu caráter interdisciplinar e sua perspectiva crítica.

No tocante a essas análises, é interessante observar que o Documento de Área de Avaliação do Serviço Social, ${ }^{1}$ de 2009, relaciona o quesito

1 “Os documentos de área são referência para os processos avaliativos, tanto na elaboração e submissão de propostas de cursos novos quanto na avaliação quadrienal dos cursos em 
inserção social com o caráter da área e sua histórica vinculação com o campo da formulação, implementação e avaliação de políticas públicas. Aponta:

Serão considerados a inserção e o impacto do Programa no desenvolvimento local, regional, nacional e internacional em termos de formação de pesquisadores e de professores da educação superior, a sua visibilidade, bem como a integração e cooperação com outros programas e centros de pesquisa e desenvolvimento profissional relacionados à área de conhecimento do Programa com vistas ao desenvolvimento da pesquisa e da pós-graduação. (Brasil, 2009, p. 3)

A inserção social é uma dimensão importante e objeto de debate político e acadêmico das representações de área do Serviço Social na Capes, entre as coordenações de programas e na Abepss. A perspectiva crítica dos rumos da pós-graduação em Serviço Social no Brasil, apontada por Mendes, Santos e Werlang (2017, p. 171), traz importantes elementos para refletir sobre essa dimensão:

No âmbito das pesquisas, compete valorizar indicadores de medida do impacto social do conhecimento produzido nos cursos de pós-graduação e a sua função social, questionar a relevância das pesquisas, como estão conectadas com os interesses da sociedade? É preciso refletir sobre a veiculação e a socialização da produção científica no campo do Serviço Social, no sentido de possibilitar visibilidade junto aos sujeitos sociais individuais e coletivos, muitas vezes sujeitos das próprias investigações realizadas.

Para o PPGSSPS, a inserção social denota a prática acadêmica, cultural e política, produtora de conhecimentos, colaborações e intervenções

funcionamento. Neles estão descritos o estado atual, as características e as perspectivas, assim como os quesitos considerados prioritários na avaliação dos programas de pós-graduação" (Brasil, 2020). 
de interesse público, organicamente articuladas com os movimentos da sociedade e sintonizadas com os fundamentos da formação/trabalho profissional e com os valores do projeto ético-político do Serviço Social. Assim, a inserção social pressupõe a articulação de dois elementos centrais: a interação entre o conjunto de atividades e ações que são próprias da pós-graduação com as necessidades e demandas da sociedade, em um fluxo de retroalimentação no contexto da Baixada Santista; e, por decorrência, a direção ético-política dessa interação e retroalimentação defendida pela área de Serviço Social.

Nessa particularidade, a defesa da direção ético-política da inserção social configura-se como uma estratégia de resistência ao avanço do conservadorismo nas práticas sociais, à voracidade do mercado financeiro sobre a política educacional e contra a pressão empresarial para produção de conhecimentos de interesse prático do setor lucrativo.

Obviamente, o tema da inserção social da pós-graduação no contexto regional é carregado de desafios, limites e tensionamentos e se coloca como uma questão:

Como priorizar, neste cenário carregado de normas, direcionamentos e políticas, uma produção com relevância social que, de fato, responda às necessidades e interesses da sociedade e que esteja a serviço da classe trabalhadora, dos movimentos sociais e de suas lutas? (Mendes, Werlang e Santos, p. 171)

Em compasso com essa demanda, a sociedade tem exigido da universidade posicionamentos e uma política de educação permanente que respondam às inúmeras indagações e necessidades oriundas de expressões da questão social na realidade regional (Unifesp, 2015).

A região da Baixada Santista ${ }^{2}$ tem papel estratégico na economia nacional e internacional por abrigar o maior porto da América Latina,

2 Composta pelos municípios de Bertioga, Cubatão, Guarujá, Itanhaém, Mongaguá, Praia Grande, Peruíbe, São Vicente, Santos. 
a indústria petroquímica e o turismo de veraneio (Viana, 2010). Dados do Índice Paulista de Responsabilidade Social (IPRS), elaborado em 2017 e 2018 pela Fundação Seade e divulgados em matéria do jornal A Tribuna (2019) apontam as contradições de um território que abarca as riquezas oriundas da pujante economia gerada pelo porto, convivendo com extremas desigualdades sociais. No estado de São Paulo, a Baixada Santista é uma das piores classificadas nesse índice que mede riqueza, escolaridade e longevidade. Dentre as dezesseis regiões paulistas está no $14^{\circ}$ lugar, com avanços na "média estadual em aspectos sociais e econômicos, mas não o suficiente para deixar as últimas posições que ocupa historicamente" (A Tribuna, 2019). Manteve a segunda colocação em termos de riquezas, abaixo apenas da região de São Paulo. Quanto aos aspectos sociais, as desigualdades são gritantes e contínuas, demarcadas pelos altos índices de mortalidade infantil perinatal, condições precárias de moradia incrustradas nos mangues, morros e nos cortiços, com insuficientes políticas de urbanização que reforçam a seletividade na ocupação urbana e o não direito à cidade.

Essa realidade regional é tomada pelo PPGSSPS como base material para engajar-se acadêmica e politicamente junto aos movimentos, lutas sociais e a órgãos responsáveis pelas políticas sociais, para propiciar a democratização do conhecimento e atuar em processos formativos no campo do trabalho, dos direitos e das políticas sociais.

A centralidade do eixo "Serviço Social e políticas sociais" que estrutura a proposta do PPGSSPS orienta a formação acadêmica, a produção intelectual e a inserção social, em conformidade com os fundamentos da formação e do trabalho profissional.

Busca-se a formação de mestrandos(as) que desenvolvam competências para "indagar-se sobre a realidade em que vivem" e elejam temas de pesquisas cuja relevância social "responda às necessidades e interesses da sociedade" (Guerra, 2011, p. 150).

O PPGSSPS, implantado na cidade de Santos, polo central da Baixada Santista, tem por base os fundamentos dos processos que configuram 
a sociedade brasileira, na qual estão inscritas as expressões e particularidades da questão social, a partir de uma concepção de totalidade.

Desde o princípio, o número de inscritos(as) nos processos seletivos tem sido grande em relação às vinte vagas. Essa demanda de interessadas(os) em um debate crítico da realidade social evidencia um indicador de sua inserção social. No ano de 2016 foram 133 candidatos(as); em 2017, 99; em 2018, 105, e no ano de 2019, 136, totalizando 473 inscritos(as). Isso demonstra uma demanda elevada pela educação permanente, exige atenção na definição de critérios de seleção e impõe ao programa a consciência de sua importância, responsabilidade e engajamento político.

Nesses quatro anos do PPGSSPS, observa-se que o perfil dos(as) mestrandos(as) é heterogêneo e plural, com diferentes formações na área das ciências sociais e humanas, com predomínio na de Serviço Social. A maioria é de trabalhador(a) do vasto campo das políticas sociais. É de conhecimento a inserção de várias(os) egressos(as) na docência e em espaços sócio-ocupacionais das políticas sociais.

Esse conjunto de elementos intensifica a responsabilidade de um programa novo, em comunicar-se com a sociedade, "produzir resistência e apresentar propostas” (Amaral, 2012, p. 236), em condições adversas de profundos ataques ao ensino e à pós-graduação.

\section{Delineando percursos e ações}

Há um empenho permanente do PPGSSPS em desenvolver e comunicar estudos, projetos e atividades que articulam sujeitos, conhecimentos e práticas. Busca enraizar-se no contexto regional, impulsionar atividades de pesquisa articuladas aos movimentos sociais, participar das lutas sociais, dos fóruns e debates locais e implicar-se com os sujeitos sociais. Inserção social construída por processos e mediações que vinculam ensino, pesquisa, trabalho técnico e gestão e resultam na práxis da universidade com a sociedade. 
Nesse percurso, elege algumas temáticas de estudos, projetos e atividades que dão materialidade à inserção social:

- Violências do Estado, direitos humanos e educação popular.

- Avaliações de políticas e programas sociais, em atendimento a demandas de instituições públicas e da sociedade civil.

- Observatório de políticas sociais e Serviço Social da região metropolitana da Baixada Santista, com ênfase nas desigualdades sociais.

- Questão étnico-racial, de gênero, feminismos e sexualidades.

- Relações de trabalho e gênero de segmentos de trabalhadores(as) locais (portuários(as), domésticas, servidoras terceirizadas da Unifesp, professoras(es) da rede municipal de educação, assistentes sociais da área sociojurídica).

- Ações de formação pesquisa e extensão sobre a rede de saúde.

- Ações de pesquisa e extensão no sistema penitenciário, nos desvendamentos do encarceramento em massa e na defesa dos direitos humanos.

- Assessoria sobre a situação das pessoas que vivem nas ruas.

- Articulação e parceria com movimentos sindicais e sociais, como movimento negro (Reflexo de Palmares e outros), movimento de mulheres (Mães de Maio e outros), Movimento de Proteção Integral de Crianças e Adolescentes, Fórum Regional dos(as) Trabalhadores(as) do Sistema Único de Assistência Social da Baixada Santista (Fortsuas-BS).

Outras inserções vêm sendo desenvolvidas a partir de intercâmbios nacionais e internacionais que articulam programas e instituições de ensino superior (IES) no Brasil, na América Latina e na Europa, como, por exemplo, as pesquisas: "O movimento de reconceituação do Serviço Social na América Latina (Argentina, Brasil, Chile e Colômbia): determinantes históricos, interlocuções internacionais e memória" e o "Serviço Social e América Latina: tendências teóricas atuais". 
Além dessas ações, o programa fomenta inovações e participações estratégicas:

1. Democratiza o acesso de estudantes trabalhadores(as) ao oferecer atividades nos períodos vespertino e noturno.

2. É um dos primeiros programas da Unifesp, juntamente com o de História, a implantar as cotas étnico-raciais e para candidatos(as) com deficiência, desde o primeiro processo seletivo. Contribuiu no debate para a elaboração da política institucional de ações afirmativas para a pós-graduação da Unifesp e também da Abepss.

3. Corpo docente com significativa inserção em associações científicas, profissionais da área e no campo das humanidades, bem como da participação de discentes na composição de:

a) Gestões da Abepss nacional e da região Sul II; coordenações de grupos temáticos de pesquisa; participação na elaboração, execução e avaliação do projeto de educação permanente Abepss Itinerante; participação discente no Fórum Nacional e Regional de Mestrandas(os) de Serviço Social.

b) Gestões do Conjunto Conselho Federal e Regionais de Serviço Social; participação na Comissão Permanente de Ética; Representação Internacional na Federação Internacional de Trabalho Social, América Latina e Caribe.

c) Comissões avaliadoras: Comissão de Área do Exame Nacional de Desempenho dos Estudantes — Enade/Inep/MEC; avaliação de cursos de graduação Inep/MEC; avaliação Nacional de Programas de Residência Multiprofissional em Saúde/MEC.

d) Centro de Antropologia e Arqueologia Forense da Unifesp; Comissão de Estudos Memórias Reveladas - Ministério de Justiça/Arquivo Nacional; Grupo de Trabalho de Promoção da Saúde da Associação Brasileira de Saúde Coletiva. 
e) Comitês editoriais de periódicos e de livros; pareceristas ad hoc de periódicos e de livros e de organismos institucionais e científicos.

Esses percursos e ações dão materialidade à inserção social assumida pelo PPGSSPS, com sua função política orientada pelos fundamentos da formação e compromissada com a sociedade.

\section{Considerações finais}

Nessa conjuntura, a tendência é de intensificação dos cortes de recursos financeiros para a pós-graduação, de cerceamento da ciência, da autonomia das universidades e do silenciamento de cientistas e pesquisadores. Observa-se que o cenário se agrava e nos convoca à resistência. Está em questão o fundamento e a direção da inserção social da universidade; entre aquilo que se "fala" e "faz" na relação com sociedade.

É importante destacar que o programa é afetado diretamente por essa conjuntura. E é justamente na apreensão dos processos sociais, na sua totalidade, que a inserção social reitera o seu significado como prática acadêmica, cultural e política, produtora de conhecimento público.

Apesar das restrições e contingências decorrentes da contrarreforma da política educacional e dos parâmetros de avaliação da Capes espelhados na lógica privatista, o programa vem resistindo a essa concepção e buscando cumprir a inserção social em outra direção, como sua função política.

No entanto, essa resistência ganha contornos de disputa de projetos de sociedade e, portanto, não pode ser solitária, específica de alguns programas, nem isolada das lutas mais amplas pelo direito à educação pública e, em especial, à pós-graduação. Exige articulação política dos programas de pós-graduação na área de Serviço Social no Brasil, capaz de agregar forças e estratégias para a defesa do projeto de formação alinhada aos compromissos éticos e políticos da profissão. 
Destarte, a inserção social precisa ser valorizada enquanto função que ocupa uma posição na política educacional, na estrutura institucional da universidade e priorizada com orçamento e status acadêmico.

\section{Referências}

ABEPSS. Contribuição da Abepss para o fortalecimento de programas de pós-graduação em Serviço Social no Brasil. 2. ed. Rio de Janeiro, nov. 2015.

AMARAL, A. S. A política nacional de pós-graduação e suas relações com o Serviço Social. Revista Katálysis, Florianópolis, v. 15, n. 2, p. 230-238, jul./dez. 2012.

BAIXADA Santista avança em aspectos sociais e econômicos, mas segue desigual. A Tribuna, Santos, 19 dez. 2019.

BOUFLEUER, J. P. Inserção social como quesito de avaliação da pós-graduação. Revista de Educação Pública, Cuiabá, v. 18, n. 37, p. 371-382. maio/ago. 2009.

BRASIL. Ministério da Educação. Coordenação de Aperfeiçoamento de Pessoal de Nível Superior. Sobre a avaliação. Disponível em: https://www.capes.gov.br/avaliacao/sobre-aavaliacao. Acesso em: 18 mar. 2020.

BRASIL. Documento de Área 2009. Disponível em: https://www.capes.gov.br/images/ stories/download/avaliacao/SERVICOSOCIAL_22jun10b.pdf. Acesso em: 18 mar. 2020.

GUERRA, Y. A pós-graduação em Serviço Social no Brasil: um patrimônio a ser preservado. Temporalis, Brasília, ano 11, n. 22, p. 125-158, jul./dez. 2011.

MENDES, J. M. R; WERLANG, R.; SANTOS, A. M. Pós-graduação em Serviço Social no Brasil: há uma pedra no caminho. Revista Katálysis, Florianópolis, v. 20, n. 2, p. 165-174, maio/ago. 2017.

RIBEIRO, R. J. Capes. Inserção social. Disponível em: https://www.capes.gov.br/images/ stories/download/artigos/Artigo_23_08_07.pdf. Acesso em: 10 jan. 2020.

UNIFESP. Proposta de criação do programa de pós-graduação em Serviço Social e Políticas Sociais/APCN, Santos, 2015.

VIANA, M. Navegando pelas ondas do desenvolvimento: Baixada Santista em busca de um porto seguro - desenvolvimento, metropolização e os (des)compassos da gestão urbano-regional em múltiplos olhares sociais. (Doutorado) - Pontifícia Universidade Católica de São Paulo, São Paulo, 2010. 


\section{Sobre as autoras}

Maria Liduína de oliveira e Silva - Coordenadora do Programa de Pós-Graduação em Serviço Social e Políticas Sociais; docente do curso de Serviço Social; assessora editorial da área de Serviço Social da Cortez Editora.

E-mail: liduoliveira90@gmail.com

Sônia Regina Nozabielli - Docente na graduação em Serviço Social e na pós-graduação em Serviço Social e Políticas Sociais da Unifesp.

E-mail: sonia.nozabielli@gmail.com

Terezinha de Fátima Rodrigues - Docente na Graduação em Serviço Social e na pós-graduação em Serviço Social e Políticas Sociais da Unifesp.

E-mail: tfrodrigues20@unifesp.br 